\title{
Pre-operative Hook-wire Localization of Thoracic Spinal Level for Intraspinal Pathology Requiring a Single Level Laminectomy
}

\author{
Muthusamy $\mathrm{KA}^{1 *}$, Abdullah BJJ ${ }^{2}$ and Waran $\mathrm{V}^{1}$ \\ Department of Surgery, University Malaya Medical Centre, Malaysia \\ Department of Diagnostic \& Imaging, University Malaya Medical Centre, Malaysia
}

Submission: January 30, 2017; Published: February 08, 2018

*Corresponding author: Kalai Arasu Muthusamy, Division of Neurosurgery, Department of Surgery, University Malaya Medical Centre, 59100 Kuala Lumpur, Malaysia, Tel: 0060123760501; Email: arasukm@um.edu.my

\begin{abstract}
The accurate localisation of the levels of the thoracic spine is important to minimise surgical trauma to the spine and soft tissue, as well reduce the possibility of spinal instability especially if bone is removed extensively to enable better exposure. The availability of techniques to minimise the need for exploration of multiple levels would go a long way in overcoming these problems. We reviewed other presently employed methods of localisation such as traditional intraoperative fluoroscopy, skin marking using radio-opaque material and dye, and computed tomography (CT) or magnetic resonance imaging (MRI) based spinal navigation system. We describe here a method of pre-operative marking of thoracic spinal level using hook-wire under CT scan control which is a simple technique for accurate identification of the level for surgery. The patients are placed prone on the CT couch. Following the performance of scouts, axial images using a spiral scan (5mm thickness with a pitch of 3) are performed. The level of the pathology is then localised. This is followed by placement of a hook-wire under the lamina of the vertebral body or the interspinous ligament. Final confirmation was obtained by repeating the CT. Intraoperatively, the vertebral target was identified easily and immediately. No errors and complications related to the technique were observed. This technique is employed successfully in our institution for the removal thoracic intraspinal pathology that requires only a single level laminectomy. This method immediately and accurately identifies the desired spinal level and minimizes the operative time.
\end{abstract}

\section{Introduction}

The accurate localization of a spinal level is important in any spinal surgery. The importance of this is not only to localize the pathology (intradural or extradural) but also to minimise surgical trauma to the spine and soft tissue, as well as reduce the possibility of spinal instability especially if extensive bone removal is required to expose the pathology. The availability of techniques to minimise the need for exploration of multiple levels would go a long way in overcoming these problems.

Many surgeons use traditional intraoperative fluoroscopy as the preferred method of identifying the vertebral level by counting the vertebra beginning from cervical or lumbarsacral vertebra. When using this technique in identifying thoracic vertebra levels becomes difficult, due to the superimposed scapular shadow and ribs.

To overcome this problem, techniques such as skin marking using radio-opaque material and dye marking using methylene blue, patent blue V dye or carbon had been used [1-3]. With the advancement in imaging techniques computed tomography (CT) or magnetic resonance imaging (MRI) based spinal navigation is becoming popular method for identifying the vertebral target $[4,5]$. Unfortunately, spinal navigational system is expensive and not available in most neurosurgical centres. We would like to describe a method of pre-operative marking of thoracic spinal level using hook-wire under CT scan control. The hookwire technique are used for preoperative localization of lesions that are deep, small, or located in an organ whose shape and position may change with the position of the patient. This technique is intended to help the surgeon find the lesion during surgery, thus allowing minimally invasive treatment.

CT-guided hookwire placement had been widely used for preoperative localization of breast microcalcifications and nonpalpable breast nodules [6]. The technique has also been used for preoperative localization of pulmonary nodules that are too small for percutaneous needle biopsy, deep osteoid osteomas, hepatic lesions, infratemporal fossa foreign bodies and deep intramuscular hemangiomas [7-9]. The aim of this paper is to describe a simple technique that providing accurate identification of the vertebral level for intradural or extradural lesions of the thoracic spine. 


\section{Technique and Clinical Result}

The placement of the hookwire is done on the morning of surgery or a day prior to surgery. The patients were taken to the radiology department for the procedure and the hook wire placement was done under CT fluoroscopy (Siemens Somatom Plus, Erlangen, Germany).

The patient is placed in prone position on the CT scan couch. A temporary radio opaque skin marker is secured to the skin just lateral to the spinous process of the vertebra corresponding to the level of pathology which is localized based on previously performed MRI sagittal scan. A lateral scout CT scan is performed.
Axial images using a spiral scan $(5 \mathrm{~mm}$ thickness with a pitch of 3) performed .The level is confirmed counting the vertebrae beginning from cervical or lumbarsacral levels. The level of pathology is again conformed from the previous MRI and the spinal lamina to be marked identified.

After thorough skin cleaning, local anaesthetic is infiltrated. The hookwire is then placed vertically over the lamina of the vertebral body or within the interspinous ligament (Figure 1a \& 1b). The final conformation is obtained by repeating the CT scan. The level at which the hookwire is placed is clearly recoded in the case note. Then the hookwire is cut $3 \mathrm{~cm}$ above the skin and secured in placed with gauze.

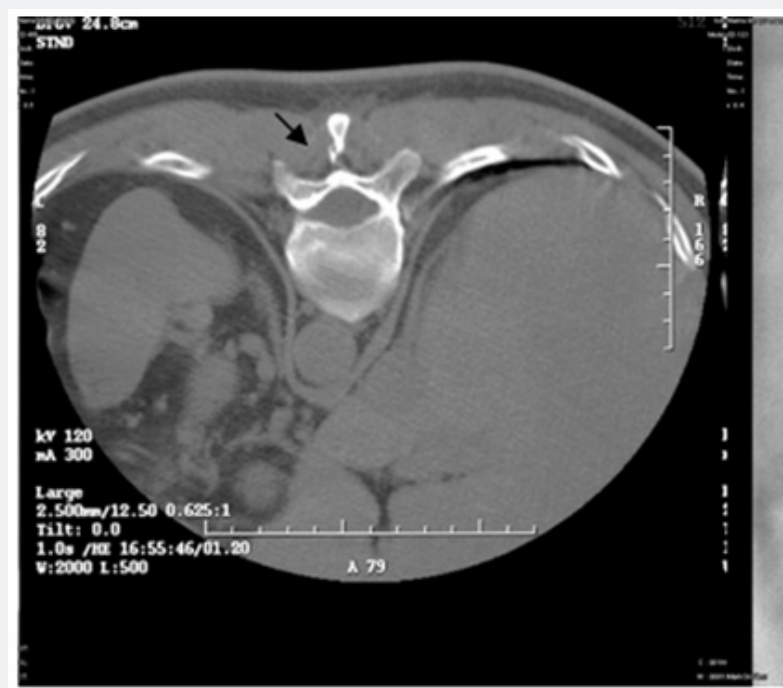

(a)

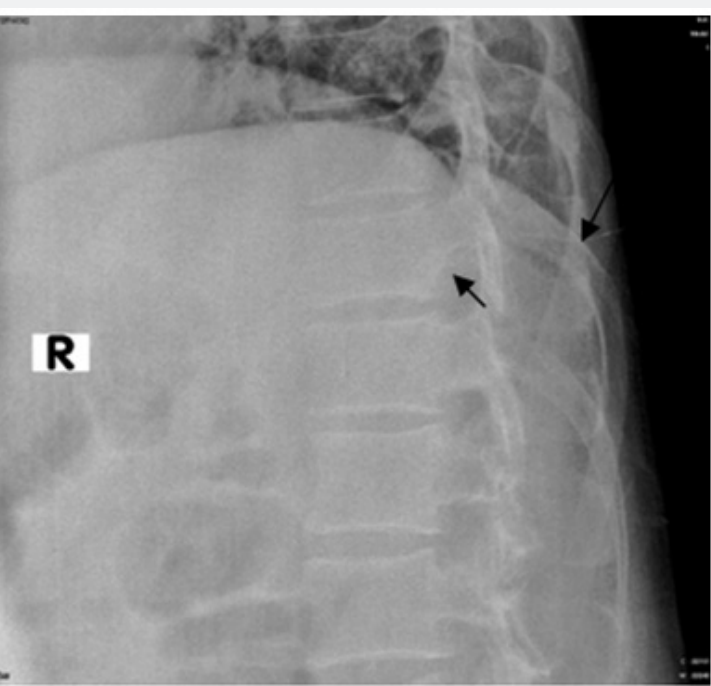

(b)

Figure 1: (a) Axial CT scan and (b) Lateral radiograph showing the hook wire (indicated by the arrow) position opposite the spinal level to be operated upon.

At surgery, patient is placed on prone position under general anaesthesia and the hook wire is exposed (Figure 2a). The patient is cleaned and draped. A midline skin incision is done at the site of the hookwire and the dissection is continued along the wire, care is taken not to burn the wire if monopolar diathermy is being used for the dissection. Once the tip is reached and the lamina is identified, the hookwire is removed (Figure 2b). The dissection is continued until the entire lamina is exposed and adequate exposure is archived. The planed laminectomy is then performed and excess to the pathology archived (Figure 3a \& 3b).

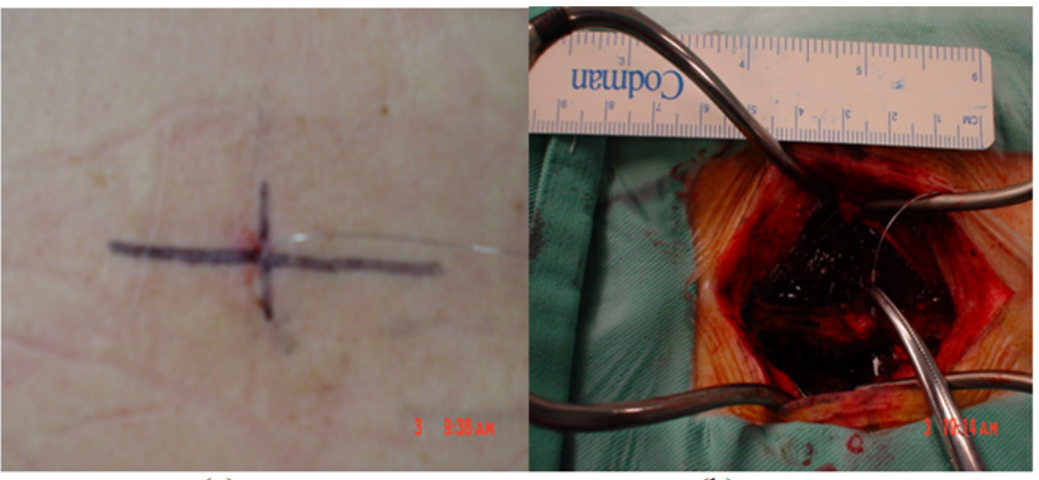

(a) (b)

Figure 2: (a) Hookwire above the skin prior to operation. (b) Hookwire tip viewed at the lamina after the dissection of soft tissue. 


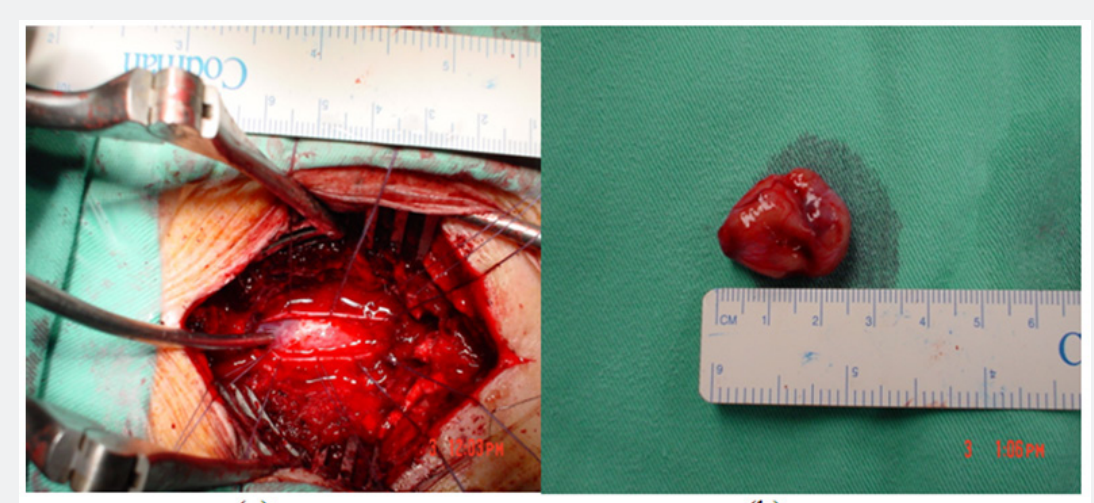

(a)

(b)

Figure 3: (a) Single level laminectomy done with dura opened. (b) Neurofibroma removed using this technique with single level laminectomy.

This technique had been used in 13 patients undergoing surgery for single level thoracic spinal lesion (intradural and extradural extramedulary lesion) located between T1 to T10. In all except one patient we were able to successfully remove the lesion using a single level laminectomy based on hook wire localization. The identification of level of lesion had been accurate with shorter operative time. There was no complication encounter using this technique.

In the single patient in whom this technique was unsuccessful, the patient was obese and we had problems in inserting the wire. The operation required an extension of the laminectomy into the next level to identify and remove the lesion.

\section{Discussion}

Intraoperative use of X-ray for localization of spinal vertebra level for intraspinal pathology had been a standard practice in most spinal surgical centers. In thoracic vertebra level, counting the level on lateral intraoperative fluoroscopy had been made difficult by the scapular shadows. The use of intraoperative fluoroscopy poses drawbacks such a prolonged operating time and exposure to ionizing radiations. To avoid these problems, other reliable techniques had been used. Paolini et al. [2] used methylene blue dye injection to the tip of the spinous process rather than the skin surface; they virtually eliminated the risk of error. The advantage of this technique is minimally invasive with markedly reduced operation time and allows identification of the marked vertebra through immediate, visual and coloured information. The limitation of the technique, is unwanted diffusion of the dye toward adjacent spinous processes but in their experience, it was avoided by taking care not to drive the needle into the interspinous ligament and injecting no more than $0.5 \mathrm{ml}$ of blue dye [2].

MRI-based technique involves preoperative application of skin markers. Several variants of this technique had been reported, each proposing a different kind of skin marker such as capsule filled with halibut liver oil, longitudinal grids of oily substance and adhesive disposable skin markers [1,10,11]. This technique has its own limitation which is pointed out by Rosahl et al. [1], that obesity, heavy skin folding and thoracic hypermobility make the procedure unreliable because of the skin shifting, which occurs while the patient is being positioned [1]. The authors recommended that application of markers in prone position would decrease the error. Even by doing so, minimal shift of these markers during positioning for surgery would shift the marker over the adjacent spinous processes which would cause an inaccurate laminectomy being done.

Spinal-navigation systems weather MRI-based or CT based is being used in many centres, this technique requires expensive equipment, extra-time in preparing the patient and the overall cost of surgery increased [4,5]. The use of hookwire for spinal level marking had only been reported by Lesoin F et al. [12] in 1986.They described the technique for localization of spinal level for dorsal disc pathology but failed to mention the success rate of this technique [12].

We used hookwire marking for localising the thoracic spinal level for intraspinal pathology which requires a single level laminectomy. We found this technique simple, fast and more reliable than the other non-navigational localizing methods. By marking the lamina or spinous process itself, rather than the skin surface, we virtually eliminated the risk of error in identifying the desired laminectomy level. This technique is also minimally invasive with limited tissue trauma. We visually eliminated the use of ionizing radiations intraoperatively. Hence, the overall operation time is markedly reduced.

Potential limitation to this technique includes dislodgement of the hookwire, breakage of wire during dissection using monopolar diathermy and infection. These problems can be avoided by attention to sterility during the insertion of wire and ensuring that the wire is well plastered down to the skin to avoid dislodgment. Dural puncture is another problem if the operator is not careful. In our experience, we did not encounter any of these problems.

\section{Conclusion}

This method immediately and accurately identifies the desired spinal level and minimizes the operative and anesthetics time. 


\section{References}

1. Rosahl SK, Gharabaghi A, Liebig T, Feste CD, Tatagiba M, et al. (2002) Skin markers for surgical planning for intradural lesions of the thoracic spine. Technical note. Surg Neurol 58(5):346-348.

2. Paolini S, Ciappetta P, Missori P, Raco A, Delfini R (2005) Spinous process marking: a reliable method for preoperative surface localization of intradural lesions of the high thoracic spine. Br J Neurosurg 19(1): 7476.

3. Redfern RM, Smith ET (1986) A method for identification of vertebral level. Ann R Coll Surg Engl 68(3): 163.

4. Bolger C, Wigfield C (2000) Image-guided surgery: applications to the cervical and thoracic spine and a review of the first 120 procedures. J Neurosurg 92(2 Suppl): 175-180.

5. Kalfas IH (2000) Image-guided spinal navigation. Clin Neurosurg 46 70-88.

6. Bronstein AD, Kilcoyne RF, Moe RE (1988) Complications of needle localization of foreign bodies and nonpalpable breast lesions. Arch Surg 123: 775-779.
7. Thaete FL, Peterson MS, Plunkett MB, Ferson PF, Keenan RJ, Landreneau RJ (1999) Computed tomography-guided wire localization of pulmonary lesions before thoracoscopic resection: results in 101 cases. J Thorac Imaging 14(2): 90-98.

8. Magre GR, Menendez LR (1996) Preoperative CT localization and marking of osteoid osteoma: description of a new technique. J Comput Assist Tomogr 20(4): 526-529.

9. Quinn PS, Sieunarine K, Brown ML, Tan P (2001) Intramuscular haemangiomas: hook wire localization prior to surgical excision: report of four cases. ANZ J Surg 71(1): 62-66.

10. Thomson JL (1988) A simple skin marker for magnetic resonance imaging. Br J Radiol 61(727): 638-639.

11. English PT, Dougal C, Griffiths PD, Gholkar A (1994) Technical note: a simple method for skin/lesion localization using magnetic resonance imaging. Br J Radiol 67(800): 813-815.

12. Lesoin F, Hermant JF, Pruvo JP, Jomin M, Rogeau P (1986) Preoperative spinal localization using the hook wire technique. Surg Neurol 25(5): 510-511.

\section{Your next submission with Juniper Publishers will reach you the below assets}

- Quality Editorial service

- Swift Peer Review

- Reprints availability

- E-prints Service

- Manuscript Podcast for convenient understanding

- Global attainment for your research

- Manuscript accessibility in different formats

( Pdf, E-pub, Full Text, Audio)

- Unceasing customer service

Track the below URL for one-step submission https://juniperpublishers.com/online-submission.php 